ISSN 1420-3049

www.mdpi.com/journal/molecules

Article

\title{
DNA-Templated Preparation of Gold Nanoparticles
}

\section{Jeong Sun Sohn ${ }^{1}{ }^{*}$, Young Wan Kwon ${ }^{2}$, Jung II Jin ${ }^{2}$ and Byung Wook Jo ${ }^{1, *}$}

1 Department of Chemical and Biochemical Engineering, Chosun University, Gwangju, 501-759, South Korea

2 Department of Chemistry, Korea University, Seoul, 136-701, South Korea; E-Mails: ywkwon@korea.ac.kr (Y.W.K.); jijin@korea.ac.kr (J.I.J.)

* Authors to whom correspondence should be addressed; E-Mails: jss4347@chosun.ac.kr (J.S.S.); bwjo@chosun.ac.kr (B.W.J.).

Received: 6 September 2011; in revised form: 19 September 2011 / Accepted: 20 September 2011 / Published: 27 September 2011

\begin{abstract}
DNA-mediated gold nanoparticles were prepared by chemical reduction of DNA-Au(III) complex. The DNA-Au(III) was first formed by reacting DNA with $\mathrm{HAuCl}_{4}$ at a $\mathrm{pH}$ of 5.6. The complex in solution was reacted with hydrazine reducing $\mathrm{Au}(\mathrm{III})$ to $\mathrm{Au}$. The reduced $\mathrm{Au}$ formed nanodimensional aggregates. The particle distributions were obtained by scanning electron microscopy (SEM) and transmission electron microscopy (TEM). This method resulted in a rather uniform dispersion of Au nanoparticles of nearspherical shape and 45 80 $\mathrm{nm}$ in diameter. Gold nanoparticles were embedded and stabilized by DNA.
\end{abstract}

Keywords: DNA-Au complexes; DNA-mediated; gold nanoparticles

\section{Introduction}

Deoxyribonucleic acid (DNA) is one of the oldest naturally occurring polymers. Since the discovery of its double helical structure, the science of DNA has been the center of biological science and biotechnology research. The most important molecular characteristic that makes DNA both attractive and successful for designing a wide variety of structures and devices resides in its molecular and submolecular recognition capabilities [1-5]. In particular, DNA has the unique capabilities to build complex nanostructures via self-assembly, which results from hydrogen-bonds formation between base pairs and hydrophilic-hydrophobic interactions. These capabilities can be utilized in the field of the 
construction of many different nanostructures using DNA as an assembly tool [6]. Moreover, structural modification of natural DNAs may induce new properties and applications that are closely related to nanobioscience and nanobiotechnology of much current interest. One of our recent articles critically reviews the materials science of DNA [4].

Chemical modification of nucleic acid has become an object of attention from the viewpoints of medicinal chemistry as well as material sciences. A nucleobase was synthesized by Tanaka et al. [7] for alternative DNA base pairing through palladium complexation. They further developed this concept by directly transforming DNA-bases into palladium-chelating nucleobases [8], but this research was based solely on the synthetic part of DNA and artificial base pairs were limited to the very small numbers found in a DNA-molecule. Aich et al. designed a metallic DNA (M-DNA) by incorporating metal into the hydrogen bonds of DNA bases [9] with divalent metal ions such as zinc, cobalt and nickel. It was reported that M-DNA might possess unusual conductive properties and behaves as a molecular wire. The most extensively studied M-DNA compositions are the complexes of DNA with platinum or palladium [10,11] since they revealed potential use as anticancer drugs. The working principle of the bio-templating approach to the preparation of metal nanowires was shown by Braun et al. [12] more than a decade ago. They suggested that the small silver aggregates, which are formed on the backbone of DNA, serve as seeds for further cluster growth. Richter et al. [13] and Mertig et al. [14] studied the formation of well-separated nanoscale size palladium clusters on a DNA template. In these approaches, the sodium ions of DNA backbone are replaced with silver or other metal ions, which is followed by the reduction of the metal ions to metals. The basic concept of DNA metallization matches the success of other approaches for direct metal-growth on biobodies such as viruses and bacteria [15-17]. The general scheme for DNA-templated growth of metal structures in three steps was discussed by Richter [18].

In this report we would like to describe an interesting approach to the preparation of gold nanoparticles by chemical reduction of DNA-Au(III) complexes formed by reacting a natural DNA with hydrogen tetrachloroaurate, $\mathrm{HAu}(\mathrm{III}) \mathrm{Cl}_{4}$. The $\mathrm{Au}(\mathrm{III})$ ions bind to the bases of DNA, whereas other metal ions such as silver and magnesium ions bind to the phosphate ions [9]. Earlier, we reported the dependence electrical conductance of a DNA-Au(III) complexes on the degree of complexation and also detailed electrical properties of a DNA-Au(III) complex fiber [19]. Complexation of DNA with $\mathrm{Au}$ (III) was thoroughly studied in the 1970s by Nandi and coworkers [20-22].

\section{Results and Discussion}

The content of $\mathrm{Au}$ in the DNA-Au(III) complex prepared in the present study, which is an intermediate, was found to be $79.80 \%$ by weight. We believe that the carbonyl oxygen atoms in guanine and thymine bases and nitrogen atoms in the imidazole rings act as complexing sites [9]. The UV-visible spectrum of the DNA-Au(III) complexes obtained at $\mathrm{pH} 5.6$ after $20 \mathrm{~h}$ of reaction is given in Figure 1a. The strong absorption below $230 \mathrm{~nm}$ resulted from absorptions of phosphate groups and sugar parts. The second maximum absorption position $\left(\lambda_{\max }\right)$ of the DNA-Au(III) complex is located at $268 \mathrm{~nm}$. This value is red-shifted when compared with the $\lambda_{\max }=260 \mathrm{~nm}$ for DNA which comes from electronic transitions of the aromatic bases. Their absorption edge position is located at about $300 \mathrm{~nm}$. 
Figure 1. UV-visible spectra of (a) DNA (black color) and DNA-Au(III) complex (red color) and (b) DNA-mediated gold nanoparticle.

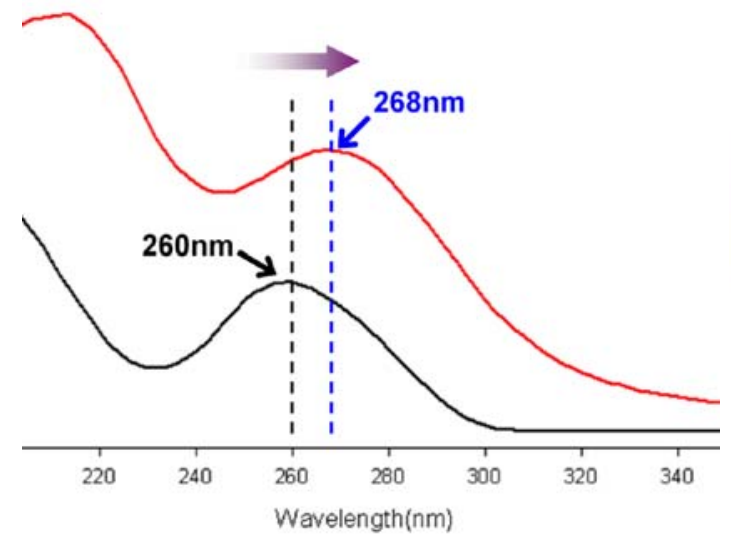

(a)

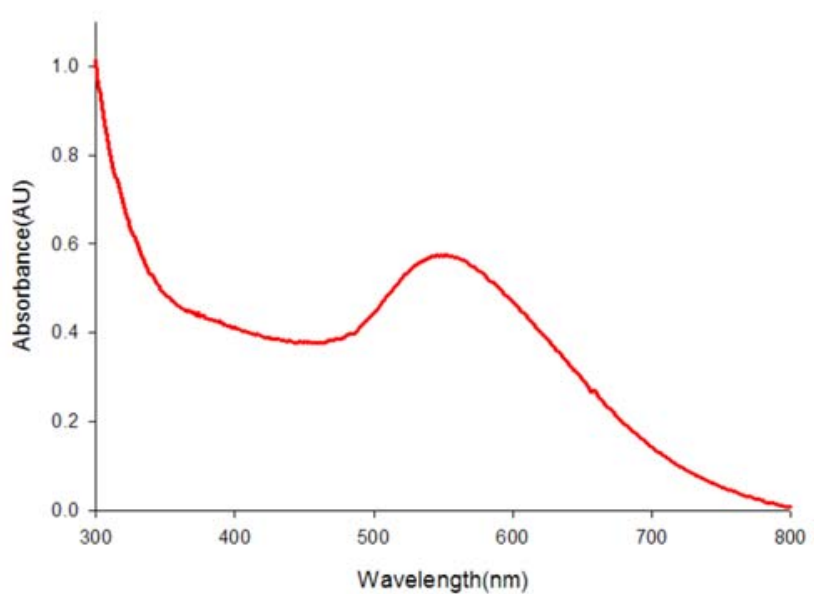

(b)

Figure 2 compares the FT-IR of DNA and DNA-Au(III) complex. In the $1800 \sim 1500 \mathrm{~cm}^{-1}$ region, in-plane base vibrations result in absorption bands particularly sensitive to base pairing and base stacking [23,24]. The $\mathrm{C} 6=\mathrm{O} 6$ guanine carbonyl group and $\mathrm{C} 2=\mathrm{O} 2$ thymine carbonyl group are known to be binding sites of metal-DNA [25]. This is reflected in a shift of the carbonyl absorption bands position to the lower side $\left(\sim 1700 \mathrm{~cm}^{-1} \rightarrow \sim 1675 \mathrm{~cm}^{-1}\right)$. On the other hand, no band shifts of thymine (C4=O4) $\left(\sim 1655 \mathrm{~cm}^{-1}\right)$ and cytosine $(\mathrm{C} 2=\mathrm{O} 2)\left(\sim 1647 \mathrm{~cm}^{-1}\right)$ carbonyl groups were observed. Absorptions in the $1500 \sim 1250 \mathrm{~cm}^{-1}$ region are caused by base sugar vibrations. The bands at $1495 \sim 1476 \mathrm{~cm}^{-1}$ characterize the imidazolic ring vibration and $\mathrm{N} 7 \mathrm{C} 8 \mathrm{H}$ bending of adenine and guanine [24]. Its intensity is decreased and a new band is appeared at $1465 \mathrm{~cm}^{-1}$, which again indicates that there is a binding between the N7 site of the guanine moiety and Au(III). Sugar-phosphate vibrations appear in the $1250 \sim 1000 \mathrm{~cm}^{-1}$ region. The antisymmetric $\mathrm{PO}_{2}^{-}$stretching band is a characteristic marker for backbone conformation and appears in the A-form at approximately $1240 \mathrm{~cm}^{-1}$ [26-28]. We cannot observe any special changes in this marker band after complexation with gold. Therefore, it is suggested that the backbone conformation of DNA mostly does not change by the formation of gold complexes and, thus, double strand configuration of gold-DNA complexes is retained.

Figure 2. FT-IR spectra of natural DNA (black color) and DNA-Au(III) complex (red color).

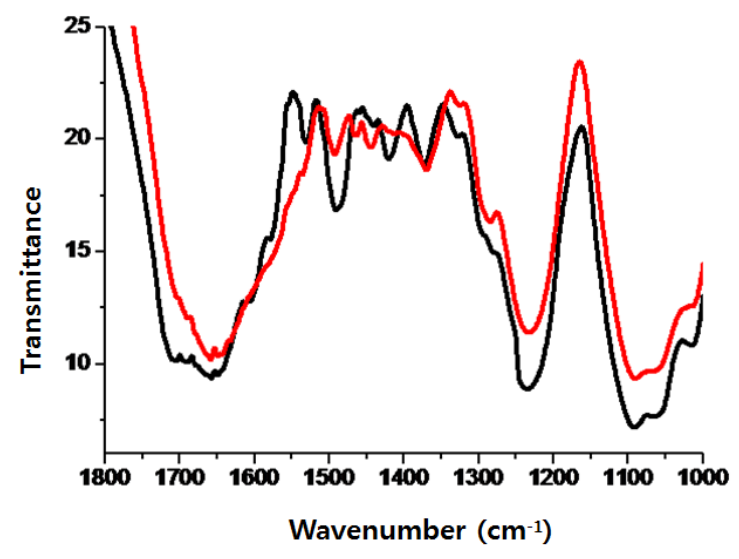


Figure $1 \mathrm{~b}$ shows the UV-vis spectrum of gold nanoparticles solution in distilled water. This solution of exhibited a characteristic absorption maximum at $550 \mathrm{~nm}$, which is known to originate from the so-called plasmon absorption by the gold nanoparticles of $45 \sim 80 \mathrm{~nm}$ in diameter. Figure 3 compares the morphology of DNA (Figure 3a) and DNA containing gold nanoparticles (Figures 3b-d). SEM images show the formation of similarly sized and shaped gold nanoparticles. In Figures $3 b-d, A u$ nanoparticles are observed in the DNA matrix. Figures $3 \mathrm{~b}$ and $3 \mathrm{C}$ are the SEM images of DNA-mediated gold nanoparticle prepared from solutions, and $3 \mathrm{~d}$ is the one prepared from washed, precipitated and dried solids. As can be seen in Figure 3c, even though the edge of nanoparticles is not well-defined, we can observe nearly spherical nanoparticles with 45 80 $\mathrm{nm}$ in diameter.

Figure 3. SEM microphotographs of (a) DNA $(\times 15.0 \mathrm{k})$, (b) low-magnification of the DNA mediated gold nanoparticle $(\times 15.0 \mathrm{k})$, and $(\mathbf{c}$, d) high-magnification of the DNA mediated gold nanoparticle $(\times 100.0 \mathrm{k})$. $(\mathbf{b}$, $\mathbf{c}$; prepared from solutions, and d; prepared from washed, precipitated and dried solids).

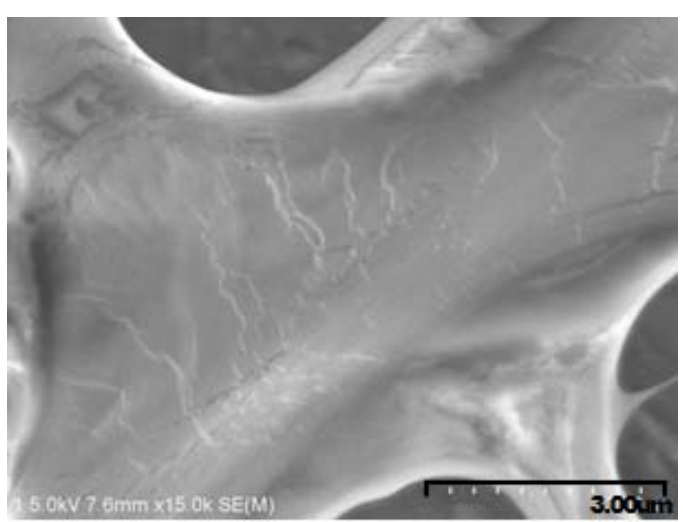

(a)

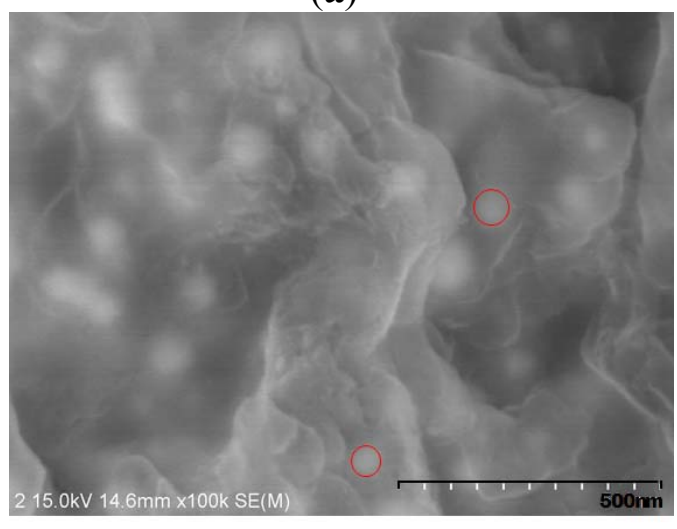

(c)

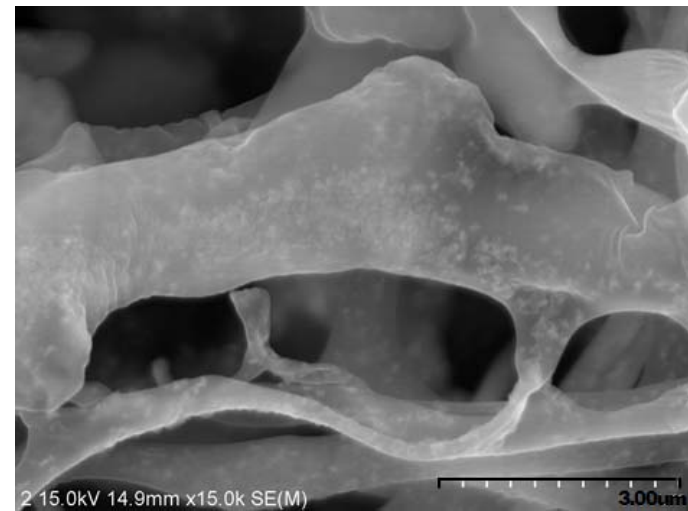

(b)

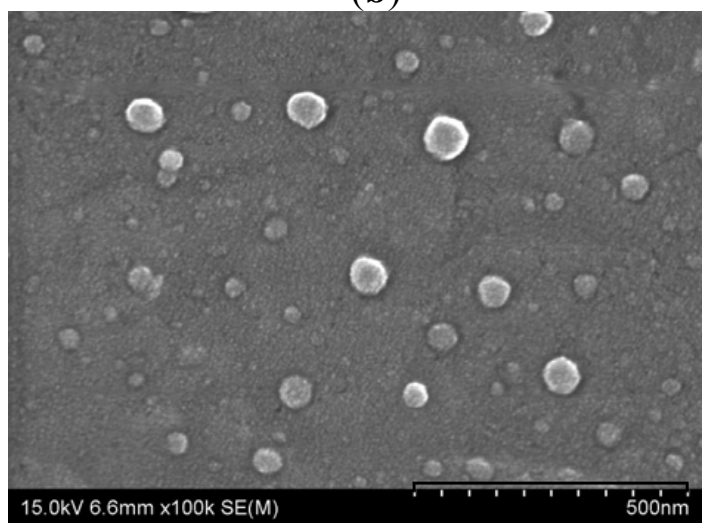

(d)

TEM images support the formation of gold nanostructures. Interestingly it is observed that DNA-mediated gold nanoparticles (Figure 4a) exhibit clusters in an aggregated form with particles smaller than approximately $10 \mathrm{~nm}$ (red circle in Figure 4b). This aggregation leads to clusters with an edge-to-edge distance of roughly $50 \mathrm{~nm}$. This behavior matches the results mentioned above. The nanoparticles also appear to be embedded in a membrane of DNA. Therefore, we can suggest that Au nanoparticles are embedded and stabilized by DNA bases with about $5 \mathrm{~nm}$ in thickness (red arrows in Figure 4). 
Figure 4. TEM images of the gold nanoparticle with DNA matrix.

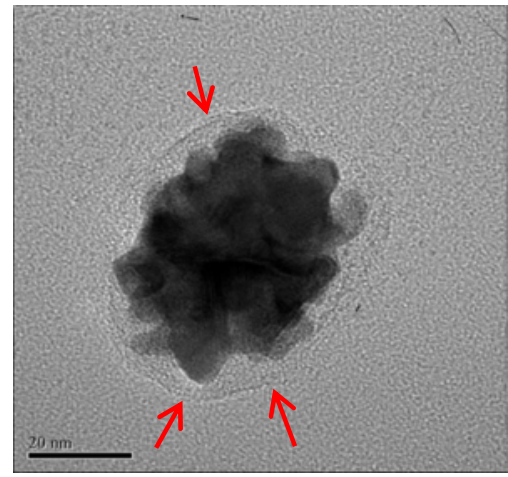

(a)

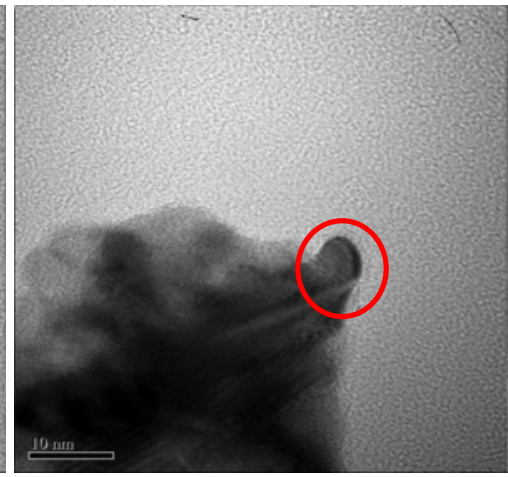

(b)

Figure 5. TEM images of gold nanoparticles in DNA matrix with different sonication times: (a) $1 \mathrm{~h}$; (b) $5 \mathrm{~h}$; and (c) $10 \mathrm{~h}$.

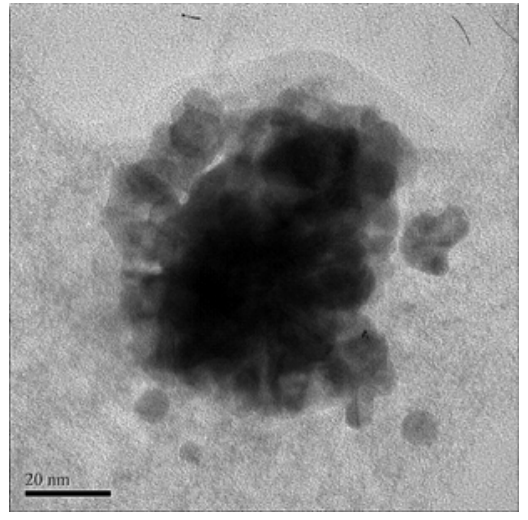

(a)

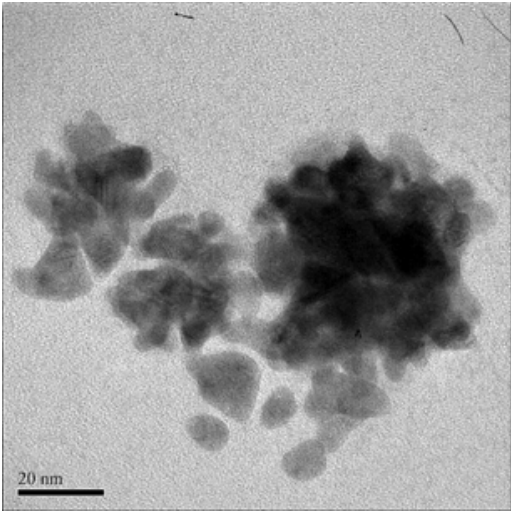

(b)

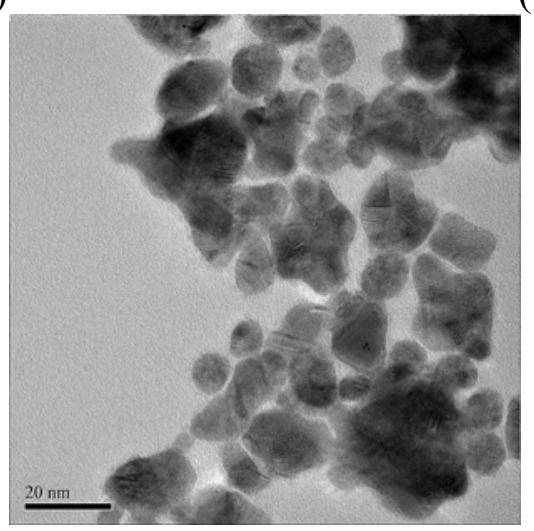

(c)

The key issue is how to stabilize Au nanoparticles by DNA bases and to obtain nanoparticles of desired dimensions with narrow size distribution. Thus, DNA-mediated gold nanoparticles were produced by a combination of the rate control for adding reductant and sonication method. Figure 5 shows the TEM images of gold nanoparticles in DNA matrix obtained after different sonication times of 1,5 and $10 \mathrm{~h}$. When the sonication time increased, aggregated nanoparticles became more disentangled. Figure $5 \mathrm{~b}$ shows the morphology of a sample after sonication for $5 \mathrm{~h}$. It shows a bimodal size distribution of large agglomerates and small particles. Especially after sonication for $10 \mathrm{~h}$, particles of several nanometers in size were observed. 
Statistics of the TEM results based on the measurement of at least 100 particles show an almost linear relationship between mean diameter and sonication time. As the sonication time was increased from $1 \mathrm{~h}$ to $10 \mathrm{~h}$, the diameter of particles decreased by several nanometers, see Figure 6 . The linearity in Figure 6 was not retained after more than $10 \mathrm{~h}$ sonication, which is beyond the limits of this study.

Figure 6. Mean diameter of DNA-mediated gold nanoparticles as a function of the sonication time.

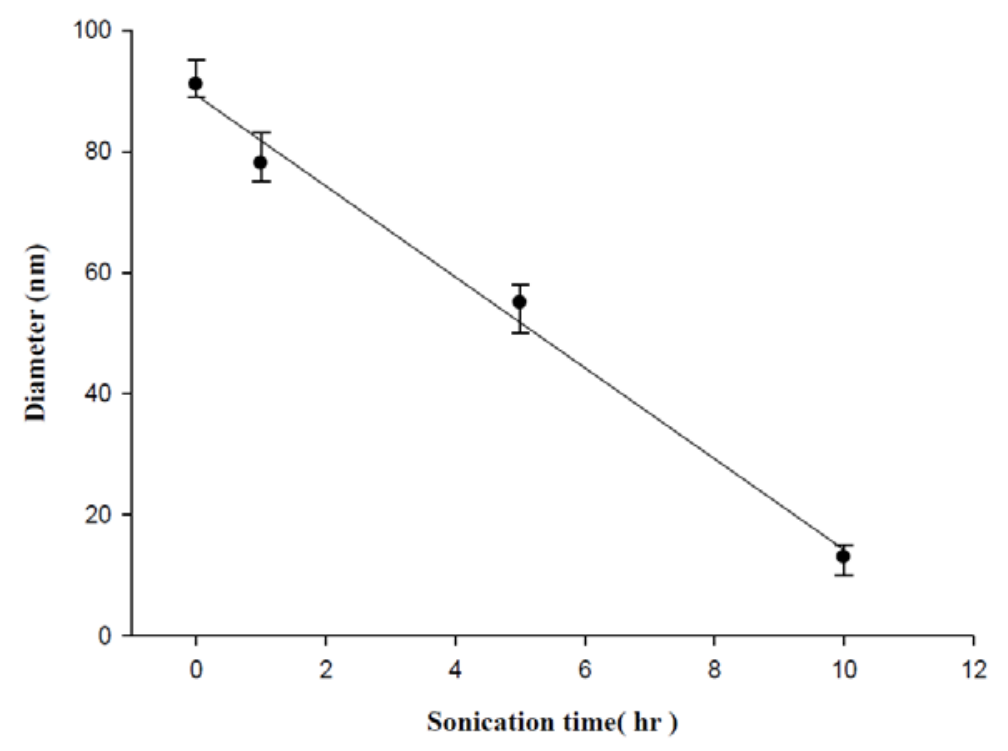

\section{Experimental}

\subsection{Materials}

Deoxyribonucleic acid (DNA) and hydrogen tetrachloroaurate(III) trihydrate were purchased from Sigma-Aldrich. DNA (Salmon sperm DNA) used in this study had a molecular weight (MW) of the order of 1.3 million Daltons (approximately 2000 bp). Hydrazine (assay 98\%) supplied by TCI was used as the reducing agent. All other chemicals and solvents were obtained from Sigma-Aldrich or TCI and used without further purification.

\subsection{Synthesis}

DNA was dissolved in acetate buffer solution $(\mathrm{pH}=5.6)$ to a final DNA concentration of $1 \mu \mathrm{M}$. The solution was swayed slowly at room temperature for $24 \mathrm{~h}$. Hydrogen tetrachloroaurate(III) trihydrate $(63 \mathrm{mg})$ was dissolved in $\mathrm{H}_{2} \mathrm{O}(6.3 \mathrm{~mL})$ at room temperature. This aqueous stock solution was added to a $1 \mu \mathrm{M}$ solution of DNA (40 mL). The resulting mixture was incubated for $24 \mathrm{~h}$ [19]. Samples of DNA-Au(III) complexes for characterization were prepared by precipitating and washing complexes repeatedly with cold ethanol. And then it was dried in vacuum. DNA-templated gold nanoparticle was synthesized by reducing the complexes solution using a solution of hydrazine: $1 \mathrm{M}$ hydrazine solution was added dropwise to diluted gold-DNA solution. 


\subsection{Characterization Methods}

FT-IR spectra were recorded on a Nicolet 6700 FT-IR spectrometer as solid KBr pellets. DNA and DNA-Au(III) complexes solutions were dropped on a silicon wafer and dried in the vacuum chamber for XPS measurements. XPS data (Table S1; see Supplementary Material) were obtained using a commercial XPS system (Thermo VG Scientific Escalab 220i-XL) and were fitted by using the commercial XPS software with a sum of $90 \%$ Gaussian and 10\% Lorentzian functions with Shirley background model. The UV-Vis absorption spectra were collected on an OPTIZEN 2120 spectrophotometer over the 200 800 nm region with a quartz cell. Au contents were determined using inductively coupled plasma atomic emission spectrometry (ICP-AES; OPTIMA 4300 DV, Perkin Elmer).

Scanning electron microscopy (SEM, Hitachi S-4800) was utilized to examine the surface morphology and particle size of gold nanoparticles. Energy dispersive X-ray spectroscopy (EDS, Figure S1; see Supplementary Material) was performed with a Hitachi S-4800 field emission scanning electron microscope (FE-SEM). FE-TEM images of gold nanoparticles were obtained using a Tecnai F20 Transmission Electron Microscope at $200 \mathrm{kV}$. Samples for TEM analysis were prepared by dropping a solution of a sample onto carbon-film $\mathrm{Cu}$ grids (400 mesh, $30 \mathrm{~nm}$ ). And then they were negatively stained by $2 \mathrm{wt} \%$ uranyl acetate solution for 1 minute, soaked with a blotting paper and dried in the air. Sonication was performed at the frequency of $40 \mathrm{kHz}$ (Power Sonic 420).

\section{Conclusions}

We demonstrated that gold nanoparticles could be prepared by chemically reducing DNA-Au(III) complexes. Further studies on the relationship between the size and size distribution of Au-nanoparticles and reaction variables such as reactant concentration, stirring rate, etc. are necessary to find optimum conditions for the preparation of Au-particles of desired size.

\section{Acknowledgements}

This study was supported by research funds from Chosun University, 2009.

\section{References}

1. Winfree, E.; Liu, F.; Wenzler, L.A.; Seeman, N.C. Design and self-assembly of two-dimensional DNA crystals. Nature 1998, 394, 539-544.

2. Seeman, N.C. DNA nanotechnology: Novel DNA constructions. Annu. Rev. Biophys. Biomol. Struct. 1998, 27, 225-248.

3. Rothemund, P.W.K. Folding DNA to create nanoscale shapes and patterns. Nature 2006, 440, 297-302.

4. Kwon, Y.W.; Lee, C.H.; Choi, D.H.; Jin, J.I. Materials science of DNA. J. Mater. Chem. 2009, 19, 1353-1380.

5. Seeman, N.C. DNA nicks and nodes and nanotechnology. Nano Lett. 2001, 1, 22-26.

6. LaBean, T.H.; Li, H.Y. Constructing novel materials with DNA. Nano Today 2007, 2, 26-35.

7. Tanaka, K.; Shionoya, M. Synthesis of a novel nucleoside for alternative DNA base pairing through metal complexation. J. Org. Chem. 1999, 64, 5002-5003. 
8. Tasaka, M.; Tanaka, K.; Shiro, M.; Shionoya, M. A palladium-mediated DNA base pair of a $\beta$-C-nucleoside possessing a 2-aminophenol as the nucleobase. Supramol. Chem. 2001, 13, 671-675.

9. Aich, P.; Labiuk, S.L.; Tari, L.W.; Delbaere, L.J.T.; Roesker, W.J.; Falk, K.J.; Steer, R.P.; Lee, J.S. M-DNA: A complex between divalent metal ions and DNA which behaves as a molecular wire. J. Mol. Biol. 1999, 294, 477-485.

10. Cisplatin: Chemistry and Biochemistry of a Leading Anticancer Drug; Lippert, B., Ed.; Wiley-VCH: Weinheim, Germany, 1999.

11. Lippard, S.J.; Berg, J.M. Principles of Bioinorganic Chemistry; University Science Books: Mill Valley, CA, USA, 1994.

12. Braun, E.; Eichen, Y.; Sivan, U.; Ben-Yoseph, G. DNA templated self-assembly of a conductive wire connecting two electrodes. Nature 1998, 391, 775-778.

13. Richter, J.; Seidel, R.; Kirsch, R.; Mertig, M.; Pompe, W.; Plaschke, J.; Schackert, H.K. Nanoscale palladium metallization of DNA. Adv. Mater. 2000, 12, 507-510.

14. Seidel, R.; Ciacchi, L.C.; Weigel, M.; Pompe, W.; Mertig, M. Synthesis of platinum cluster chains on DNA templates: Conditions for a template-controlled cluster growth. J. Phys. Chem. B 2004, 108, 10801-10811.

15. Kirsch, R.; Mertig, M.; Pompe, W.; Wahl, R.; Sadowski, G.; Bohm, K.J.; Unger, E. Three-dimensional metallization of microtubules. Thin Solid Films 1997, 305, 248-253.

16. Shenton, W.; Douglas, T.; Young, M.; Stubbs, G.; Mann, S. Inorganic-organic nanotube composites from template mineralization of tobacco mosaic virus. Adv. Mater. 1999, 11, 253-256.

17. Mertig, M.; Kirsch, R.; Pompe, W.; Engelhardt, H. Fabrication of highly oriented nanocluster arrays by biomolecular templating. Eur. Phys. J. D 1999, 9, 45-48.

18. Richter, J. Metallization of DNA. Physica E Low Dimens. Syst. Nanostruct. 2003, 16, 157-173.

19. Hwang, J.S.; Hong, S.H.; Kim, H.K.; Kwon, Y.-W.; Jin, J.-I.; Hwang, S.W.; Ahn, D. Electrical transport properties of Au-doped deoxyribonucleic acid molecules. Jpn. J. Appl. Phys. 2005, 44, 2623-2625.

20. Pillai, C.K.S.; Nandi, U.S. Binding of Gold(III) with DNA. Biopolymers 1973, 12, 1431-1435.

21. Pillai, C.K.S.; Nandi, U.S. Interaction of metal ions with nucleic acids and related compounds. II. Studies on Au(III)-nucleic acid system. Biopolymers 1978, 17, 709-729.

22. Mandal, C.; Nandi, U.S. Kinetic studies on the interaction of Gold(III) with nucleic acids. IV. RNA-Au (III) system. Chem. Biol. Interact. 1978, 21, 125-134.

23. Hadjiliadis, N.; Pneumatikakis, G.; Basosi, R. Gold complexes of purine and pyrimidine nucleosides. J. Inorg. Biochem. 1981, 14, 115-126.

24. Banyay, M.; Sarkar, M.; Graslund, A. A library of IR bands of nucleic acids in solution. Biophys. Chem. 2003, 104, 477-488.

25. Pneumatikakis, G.; Hadjiliadis, N.; Theophanides, T. Complexes of inosine, cytidine and guanosine with Pd(II). Inorg. Chem. 1978, 17, 915-922.

26. Shimanouchi, T.; Tsuboi, M.; Kyogoku, Y. The Structure and Properties of Biomolecules and Biological Systems; In Infrared Spectra of Nucleic Acids and Related Compounds; Duchesne, J., Ed.; Interscience: London, UK, 1964; p. 435. 
27. Tsuboi, M.; Takahasi, S.; Harada, I. Physico-Chemical Properties of Nucleic Acids. In Infrared and Raman Spectra of Nucleic Acids-Vibrations in the Base-Residues, Duchesne, J., Ed.; Academic Press Inc: London, UK, 1973; p. 91.

28. Liquier, J.; Taillandier, E. Infrared Spectroscopy of Biomolecules. In Infrared Spectroscopy of Nucleic Acids, Mantsch, H.H., Chapman, D., Eds.; Wiley-Liss Inc: New York, NY, USA, 1996; p. 131.

Sample Availability: Not available.

(C) 2011 by the authors; licensee MDPI, Basel, Switzerland. This article is an open access article distributed under the terms and conditions of the Creative Commons Attribution license (http://creativecommons.org/licenses/by/3.0/). 